\title{
Explaining the Diffusion of Web-Based Communication Technology among Congressional Offices: A Natural Experiment using State Delegations
}

\section{Citation}

Esterling, Kevin, David Lazer, and Michael Neblo. 2009. Explaining the Diffusion of Web-Based Communication Technology Among Congressional Offices: A Natural Experiment Using State Delegations. HKS Faculty Research Working Paper Series RWP09-029, John F. Kennedy School of Government, Harvard University.

\section{Published Version}

http://web.hks.harvard.edu/publications/workingpapers/citation.aspx?Publd=6777

\section{Permanent link}

http://nrs.harvard.edu/urn-3:HUL.InstRepos:4481606

\section{Terms of Use}

This article was downloaded from Harvard University's DASH repository, and is made available under the terms and conditions applicable to Other Posted Material, as set forth at http:// nrs.harvard.edu/urn-3:HUL.InstRepos:dash.current.terms-of-use\#LAA

\section{Share Your Story}

The Harvard community has made this article openly available.

Please share how this access benefits you. Submit a story. 


\title{
MARVARD Kennedy School \\ JOHN F. KENNEDY SCHOOL OF GOVERNMENT
}

\author{
Faculty Research Working Papers Series
}

\section{Explaining the Diffusion of Web-Based Communication Technology among Congressional Offices: A Natural Experiment using State Delegations}

\author{
Kevin M. Esterling \\ University of California, Riverside \\ David Lazer \\ Northeastern University \\ John F. Kennedy School of Government - Harvard University \\ Michael A. Neblo \\ Ohio State University
}

September 2009

RWP09-029

The views expressed in the HKS Faculty Research Working Paper Series are those of the author(s) and do not necessarily reflect those of the John F. Kennedy School of Government or of Harvard University. Faculty Research Working Papers have not undergone formal review and approval. Such papers are included in this series to elicit feedback and to encourage debate on important public policy challenges. Copyright belongs to the author(s). Papers may be downloaded for personal use only. 


\title{
Explaining the Diffusion of Web-Based Communication Technology among Congressional Offices: A Natural Experiment using State Delegations ${ }^{1}$
}

\author{
Kevin M. Esterling \\ (Corresponding Author) \\ Associate Professor \\ Department of Political Science \\ UC-Riverside \\ kevin.esterling@ucr.edu \\ David M.J. Lazer \\ Associate Professor of Political Science \\ and Computer Science \\ Northeastern University \\ davelazer@gmail.com \\ Michael A. Neblo \\ Assistant Professor \\ Department of Political Science \\ Ohio State University \\ neblo.1@osu.edu
}

August 25, 2009

\footnotetext{
${ }^{1}$ Prepared for presentation at the Annual Meetings of the American Political Science Association, Toronto, Canada, September 2-5, 2009. This project is funded by a grant from the Digital Government Program of the NSF (award number IIS-0429452). We gratefully acknowledge the intellectual contributions from our colleagues at the Congressional Management Foundation (CMF), especially Collin Burden, Nicole Folk-Cooper, Kathy Goldschmidt, and Tim Hysom. Any opinions, findings, and conclusions or recommendations expressed in this material are those of the authors and do not necessarily reflect the views of the National Science Foundation or CMF.
} 


\begin{abstract}
Do legislators learn to use new communication technologies from each other? Using data from the official homepages of members of the U.S. House of Representatives, we test whether web-based communication technology diffuses through congressional state delegations. We use a natural experimental design that exploits ignorable state boundaries to distinguish between causal diffusion processes and spatial heterogeneity. Using nonlinear conditional autoregressive models for the statistical test, we find that web communication technology practices are weakly driven by communication within state delegations, and with the effect slightly more pronounced among Democrats than among Republicans.
\end{abstract}




\section{Introduction}

The practice of representation is central to any legislator's responsibilities, both normatively (Pitkin, 1967) and empirically (Fenno, 1978). The relatively recent development of Internetbased communication technologies has the potential to transform the way legislators engage in these practices (Druckman, Hennessy, Kifer, and Parkin, 2009; Druckman, Kifer, and Parkin, 2007). As with technological innovation in any occupational field, legislators must learn how to adopt and implement these new communication technologies. In this paper, we examine whether this learning occurs among members of the U.S. House of Representatives, focusing on the extent of diffusion of web-based communication technologies among representatives' official homepages. It is well known within the literature on Congress that members often discuss legislative issues and procedures with other members from their state delegation (Truman, 1956). We therefore expect that a member will be more (less) likely to adopt new website communication practices if other members of her state delegation have (have not) adopted the practices.

A vast array of studies in other organizational settings highlights the critical role that informal networks play in the adoption of innovations (Rogers, 1976). Further, there is a substantial literature on the important role networks play within the Washington system more generally (Carpenter, Esterling, and Lazer, 1998, 2003, 2004, Heinz, Laumann, Nelson, and Salisbury, 1993; Laumann and Knoke, 1984) as well as some research on interconnections among state legislators. There has been little research on the informal mechanisms of the diffusion of technical innovations in the congressional system, however - a system that includes not just 435 members of the House of Representatives and 100 Senators, but many thousands of staff members as well. More generally, there is very little research on the informal network of the members of the congressional system and the impact of that network on the decisions of Congressional offices (for exceptions, see Baughman, 2006; Fowler, 2006).

We hypothesize that attention to website communication technology will diffuse through informal communication networks defined by membership in state delegations, that is, among 
members that happen to share a geographic physical proximity. A major inferential issue in testing the effects of spatial diffusion, or diffusion among physically proximate units, is to distinguish a diffusion process from a process driven simply by unmeasured confounding variables that are spatially correlated with the communication network (see Lazer, 2001). As we describe below, we are able to take advantage of a quasi-experiment to identify the causal effect of diffusion, exploiting the ignorable $\oint^{1}$ state boundaries that define the state delegation communication network. Using data on the technology adoptions of neighboring congressional districts, some of which are across state lines, we are able to control for unobserved spatially-distributed heterogeneity, and so we can identify the causal effect of membership in a state delegation on technology adoption. Our results suggest that the state delegation informal networks play a perceptible, but not major, role in the diffusion of website communication technologies among congressional offices, and that this diffusion is somewhat greater among Democrats than among Republicans.

This paper is divided into four sections. The first section reviews the literature on the role social networks play in diffusion of innovations, focusing on what we know about the informal networks within legislatures. The second section summarizes the research design and data we will be examining, and the third presents our statistical analyses. The final sections discuss our results and implications for future directions in this vein of research.

\section{State Delegations and the Diffusion of Website Com- munication Technology}

The role of social networks is probably the single most studied driver of the diffusion of innovations (Coleman, Katz, and et al, 1957; Hagerstrand, 1967; Ryan and Gross, 1943). Learning through observing others' experiences lowers the ambiguity and perceived risk associated with an innovation Galaskiewicz and Burt, 1991; Haunschild and Milner, 1997; Valente, 1995). Further, the behaviors of others creates a normative environment. A be-

\footnotetext{
${ }^{1}$ Ignorability in this context requires that the distribution of unobserved variables are not affected by where the state boundary line is drawn. We test for this ignorability below.
} 
havior is legitimate because others who are similarly situated are doing it, inducing mimetic isomorphism (DiMaggio and Powell, 1983).

Social network research has found that strong or "high bandwidth" relationships - those based on personal familiarity, trust, and high frequency - are especially important for the exchange of complex, tacit, or confidential knowledge (Hansen, 1999). A number of studies in the social networks literature show, for example, that physical co-location increases job related communication in work groups, because proximity tends to drive and facilitate regularized communication den Bulte and Moenaert, 1998). Co-location or spatial proximity itself will not lead to an increased communication- they are just prerequisites for higher exposure, more frequent informal occasions where people meet in the hallways or other social areas within office buildings. These meetings in turn increase the probability of informal communication regarding successful technology practices Allen, 1978; Festinger, 1950; Kraut, Egido, and et al, 1990; Monge, Rothman, and et al, 1985; Rice and Aydin, 1991; Zahn, 1991). Walker's (1969) classic study of the diffusion of innovations among the American states shows that diffusion tends to occur more regularly among adjacent states, which he took to proxy for more regular communication among state-level policy activists (see also Mintrom, 1997).

In the present case, the adoption of Web-based communication technologies is largely public; all Member web sites are public. The logic and experience underlying particular decisions is private, however, and this private information is unevenly distributed. The role of informal advice networks (who asks whom for advice regarding their web sites) and attention networks (who pays attention to whom) are likely fairly powerful with respect to Members of Congress. Thus, for example, it might require repeated interactions and high levels of familiarity between two chiefs of staff from Members' offices to effectively transfer the knowledge about implementation challenges with respect to particular web-based practices.

The tendency of members from the same state to meet and discuss policy and process legislative issues is well known in the literature on Congress (Truman, 1956). At the state 
level, Caldeira and Patterson (1987) find similar patterns of friendship among Iowa state legislators with districts closer together. Arnold, Dean, and Al (2000) purport ${ }^{2}$ to demonstrate that friendship ties among Ohio state legislators causes members to more often vote on the same side of issues, holding other causes of members' vote similarity constant. As we mention above, there has been very little research on the potential influence of social networks within the US Congress because of the practical challenges in collecting social network data from congressional offices $3^{3}$ In this paper, we test whether diffusion of website technologies occurs through state delegations.

\section{Distinguishing Spatial Heterogeneity from Diffusion using a Natural Experiment}

The major inferential issue in testing hypotheses about diffusion among geographicallyproximate units involves distinguishing a diffusion process from mere spatial heterogeneity, where omitted confounding variables exist that are correlated with spatial network patterns Congdon 2003, 274; Lazer 2001). If the websites of the members of a state delegation are all likely to have a given characteristic, and websites in another state are unlikely to, we wish to be able to test whether this correlation is due to a causal diffusion process, or due to a spurious dependence where many members of a state delegation may happen to share an unobserved causal variable. If the latter is true, we would only observe heterogeneity between state delegations, and this is only observationally equivalent to a diffusion process. To address this, we make use of the ignorable state boundaries that define state delegations in a quasi-experimental design intended to distinguish heterogeneity from causal diffusion.

Using conditional autoregressive (CAR) models (Congdon, 2003, 278-282), we are able to control for spatial heterogeneity by exploiting data from other members whose congressional

\footnotetext{
${ }^{2}$ Unfortunately their results are questionable because their OLS analysis is vulnerable to the criticisms of spuriousness that we describe below. In short, the non-random assignment of nodes to network locations raises inferential problems that are very common in studies of social network analysis.

${ }^{3}$ Notable exceptions include Baughman (2006), who shows how informal staff communication among members who have overlapping committee assignments reduces the transaction costs for writing and negotiating legislation, and Fowler (2006), who examines co-sponsorship networks.
} 
districts are adjacent to each other. If spatially confounding variables exist, they would most likely be evident in these localized networks, since adjacent congressional districts share more similarities than districts in opposite ends of the state. For example, the California $45^{\text {th }}$ district (including the desert cities of Palm Springs and Indio) shares more similarities with the Arizona $7^{\text {th }}$ district (parts of Yuma, Maricopa and Pima desert counties) than with the California $6^{\text {th }}$ district (wine country, Marin and Sonoma counties). Assuming relevant spatially distributed variables are not conditioned by state boundaries, evidence is lent in support of spatial diffusion as opposed to mere heterogeneity if, controlling for spatial heterogeneity among adjacent districts, members' web communication practices are causally dependent within networks defined by state delegation.

One can see the logic of this natural experimental design in figure 1. This figure takes congressional district $D=\{6\}$ as the "subject" district (the estimator of course repeats the analysis for all 438 districts in the dataset). $D$ is in state $\mathrm{X}$, and is directly adjacent to seven other districts: $O=\{3,4,5,7\}$ also in state $\mathrm{X}$, and $C=\{11,13,14\}$ that are in states $\mathrm{Y}$ and $\mathrm{Z} ; A=\{O \cup C\}$ is the full set of adjacent districts. The state delegation for state $\mathrm{X}$ is composed of districts $S=\{1,2, \ldots, 9\}$, and in this delegation, only $T=\{1,2,89\}$ are not adjacent to $D$. The experimental design assumes that the adjacent districts $A$ have the most similar values on unobserved variables to $D$. The set $C \subset A$ serves as a true control group, analogous to a "pretreatment" condition, since these districts are not in $S$. The set $T=S / O$ is the exposure to the treatment, analogous to a "post treatment" condition. The set $O=\{A \cap S\}$ are only partial controls since in this region the treatment condition (being in the set $S$ ) and the control condition (being in set $A$ ) overlap.

The statistical estimator uses the outcome data from the districts in A to create an experimental "pretreatment" baseline, and holding this baseline constant, estimates the post treatment effect of being in set $S$. So for example, consider the effect of being in delegation $S$ on whether or not a member chooses to have a blog on her official webpage. The model dynamically estimates 1$) \mathrm{p}(A)$ equal to the average propensity of the districts 


\section{The Logic of the Natural Experiment}

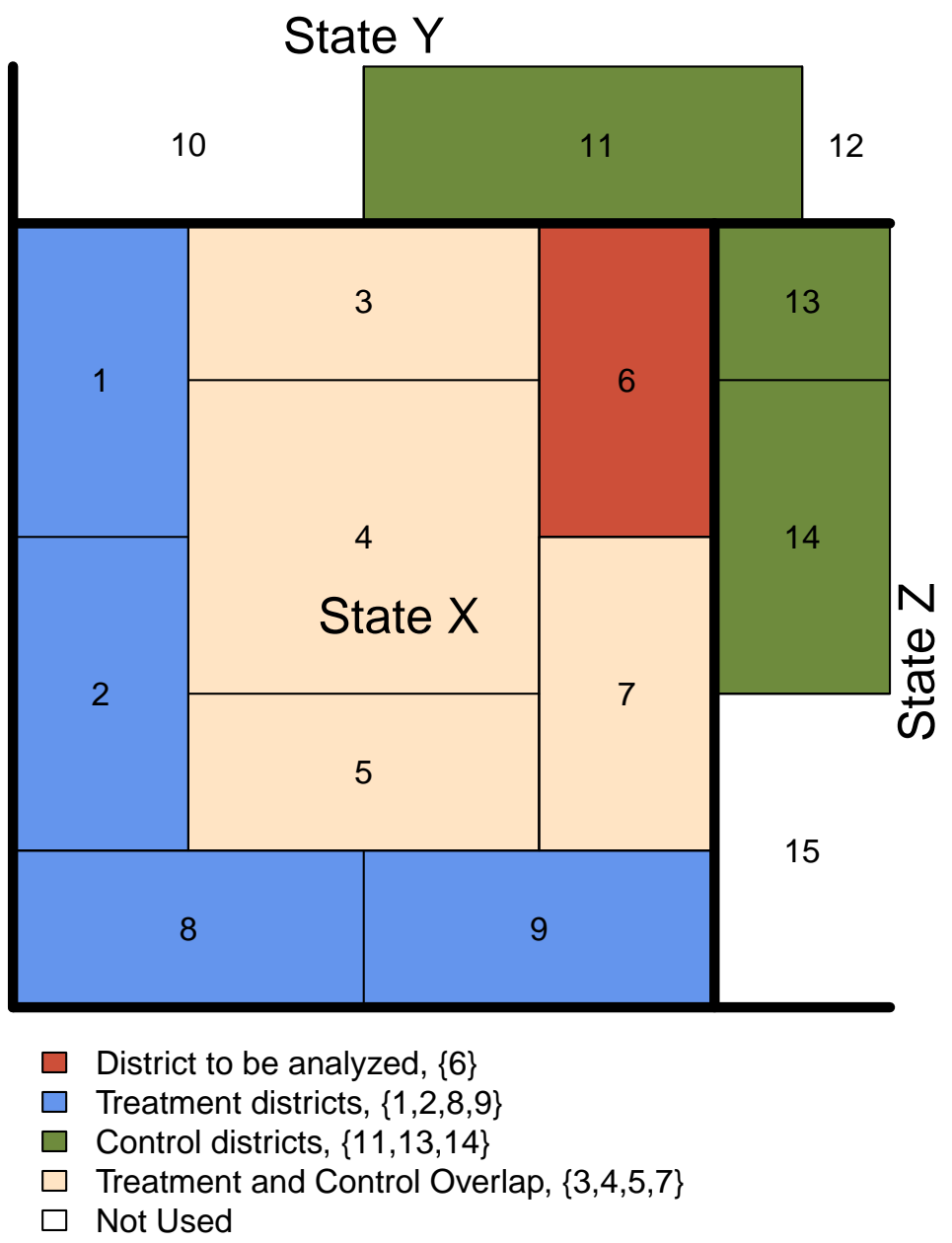

Figure 1: The Logic of the Natural Experiment

in $A$ to have a blog on their web pages, 2) $\mathrm{p}(S)$ equal to the average propensity of the districts in $S$ to have a blog on their web pages, and 3) holding $\mathrm{p}(A)$ constant, the model estimates the effect of $\mathrm{p}(S)$ on the propensity for $D$ to have a blog on her website $4^{4}$ One can think of this design as similar to a random effect model that identifies a pretreatment condition, where the adjacent districts in $C$ serve as "repeated observations" for district $D$ in the pretreatment control condition, and the districts in $T$ represent the exposure in the

\footnotetext{
${ }^{4}$ As we describe below, $\mathrm{p}(A)$ and $\mathrm{p}(S)$ are the posterior distribution of these propensities, and so the model accounts for the full distributions of each, not simply their point estimates.
} 
post treatment condition. The districts in $S$ and in $A$ necessarily have some overlap (their union is never null); the greater the overlap the fewer districts in $T$, and hence the more conservative is the treatment effect estimator. Thus, the model gets the most purchase on the treatment effect from states that lie on a state border. (294 out of 438 districts lie on a border, or about 67 percent of districts).

The persuasiveness of this quasi-experimental approach depends critically on the ignorability of state boundaries for unobserved spatially distributed confounding variables. This assumes there is nothing about the location of the state border that affects citizens' location patterns or the qualities of members that are in districts that are geographically proximate, but on either side of the state line. For example, this assumption holds that residents in the Louisville area would equally likely choose to live in New Albany, Indiana, across the Ohio River, as they would a Kentucky-side suburb, and members that serve in each type of suburb share similar qualities. One would also expect that New Albany will differ demographically and politically from South Bend or Kokomo.

We can test for the ignorability of state boundaries using aggregate district level census data. If the state borders are ignorable, then aggregate census data should be balanced between districts that are on either side of the state border, among those that are adjacent to a district that lies on a border. That is, census data should be balanced between the districts in $O$ and $C$ when stratified for each border congressional district. At the same time, one would not expect census data to be balanced between districts in the control set $C$ and those in the treatment set $T$. We test balance only among the 242 districts that lie adjacent to a border and that are in a state large enough to have districts that are within the state but not adjacent (55 percent of districts in the sample meet these conditions). For covariates we use current census data on district median income; the percent of the district residents that are college educated; in the service employment sector; the blue collar sector; under 18; Hispanic; Asian; Black; residentially rural; and the percent voting for Kerry in the 2004 general election. Using the omnibus balance test statistic of Hansen and Bowers 
(Hansen and Bowers, 2008), we cannot reject the hypothesis of balance between $O$ and $C(p=0.881)$, but we can reject the hypothesis of balance between $C$ and $T(p=0.056)$.

While this exogeneity is true for these observed variables, the assumption still may be violated in several ways. For example, it is possible that state level education, tax or other social policies can affect citizens' location decisions and these can affect relevant variables not measured in the census. Or it is possible that the recruitment patterns of members differ across states, for example if the parties have different organizational structures across states.

Note that a failure to rule out spatial heterogeneity does not disprove the diffusion hypothesis; if correlations are evident within both the district-adjacencies network and the state delegation network, this simply leaves the two processes, heterogeneity and diffusion, as observationally equivalent. An observed correlation within the district adjacency network but not within the state delegation network would lend evidence in favor of heterogeneity. Finally, no observed correlations within either network would simply suggest that website practices are independent within both networks (but not necessarily within conceivable, unmeasured networks).

\section{Data}

Within the U.S. House of Representatives, congressional offices are 440 (including nonvoting delegates) small, functionally identical, public organizations with a set of policy and procedural outputs (Hedlund, 1984, Salisbury and Shepsle, 1981). This enables a large $N$ statistical study of innovation adoption. Below we discuss the innovations that we are studying - website communication technologies - as well as control variables that we have shown elsewhere (Esterling, Lazer, and Neblo, 2005) are important drivers of website quality, and how we created the district adjacency and state delegation matrices. 
Table 1: Descriptive Statistics

\begin{tabular}{lcrr} 
& Scale & Mean & SD \\
\hline Blog & $0-1$ & 0.05 & 0.22 \\
Podcast & $0-1$ & 0.04 & 0.20 \\
Text Only & $0-1$ & 0.07 & 0.25 \\
Audio & $0-1$ & 0.16 & 0.37 \\
Video & $0-1$ & 0.36 & 0.48 \\
RSS Feed & $0-1$ & 0.10 & 0.29 \\
Look \& Feel & $1-5$ & 3.26 & 1.01 \\
Navigation & $1-5$ & 3.50 & 0.88 \\
Readability & $1-5$ & 3.20 & 0.83 \\
Organization & $1-5$ & 3.43 & 0.82 \\
Timeliness & $1-5$ & 3.14 & 0.91 \\
\hline$N=438$ & & &
\end{tabular}

\subsection{Outcome variables}

The dependent variables we use for this analysis are drawn from the 2006 Congressional Management Foundation (CMF) coding of the official web site for each member of Congress ${ }^{5}$ The coding for these variables, and the instructions given to the coders, are listed in appendix table 2. The descriptive statistics for the dependent variables are listed in table 1 .

The first six items measure the presence or absence of a number of technological features of websites that enhance communication. These are the presence of a Blog, Podcasting capability, the ability to read the page in Text only, the presence of Audio and Video, and support for $R S S$ feed. Note that none of these items are especially prevalent on congressional websites in 2006. For example, only five percent of members had a blog, and only 10 percent had support for RSS feed. The final five items measure general technical properties of the website design, and are all rated on a one to five scale. These include the Look $\&$ feel of

\footnotetext{
${ }^{5}$ In the summer of 2006 , CMF coded each official website based on nearly 100 operational criteria. These items tap into what makes for a good House website in the normative sense - i.e., whether the website both communicates information constituents want to see on websites, and information the member wants constituents to know. The criteria were identified using a number of sources: asking focus groups of citizens to spend time on a sample of sites, interviews and surveys with office staff and citizens, as well as Web industry research. For more detail on the coding dimensions, intercoder reliability, and other technical issues, see the 2006 "gold mouse" award report, http://www. cmfweb.org/index.php?option=com_content\&task= view\&id=198\&Itemid=60
} 


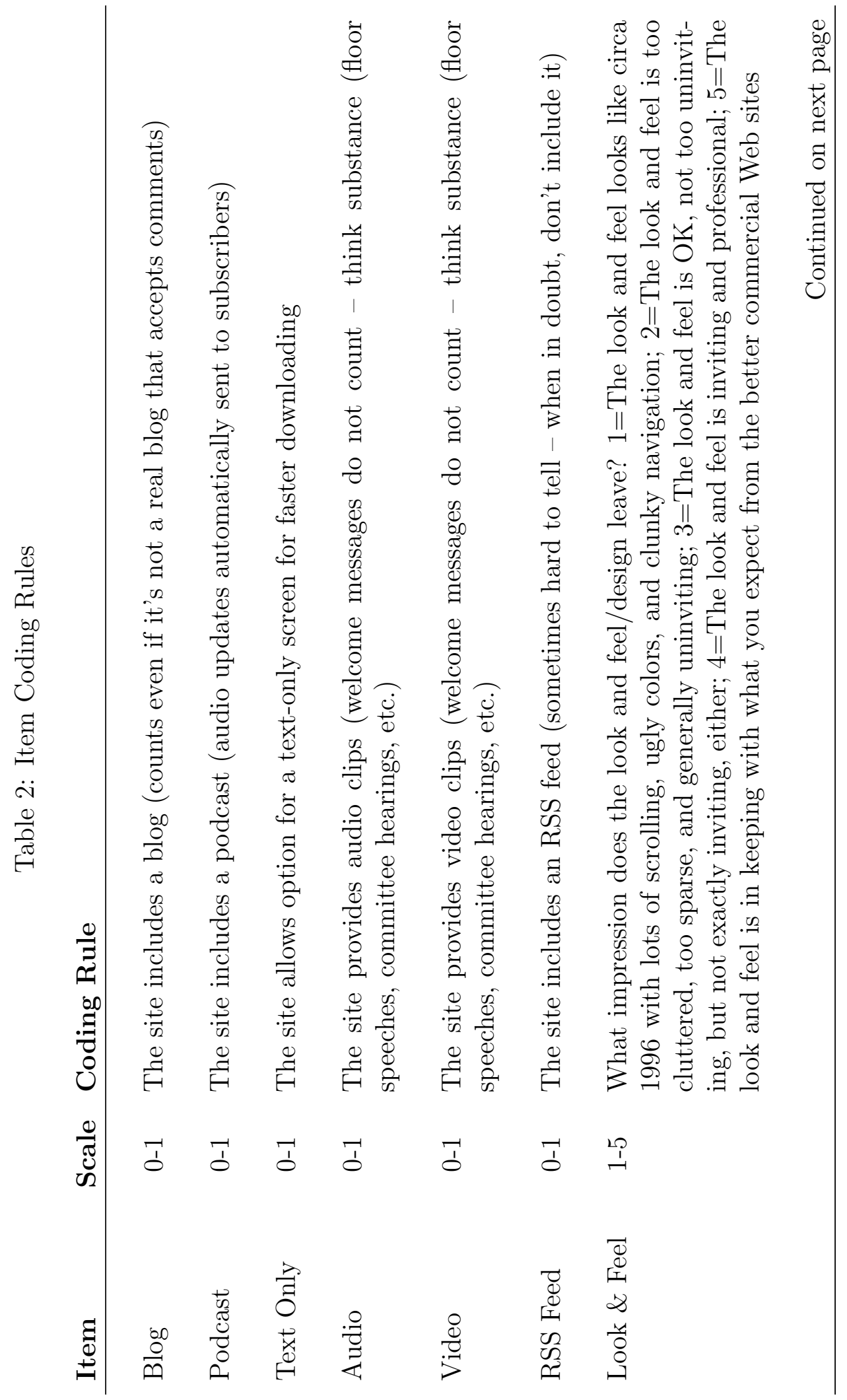




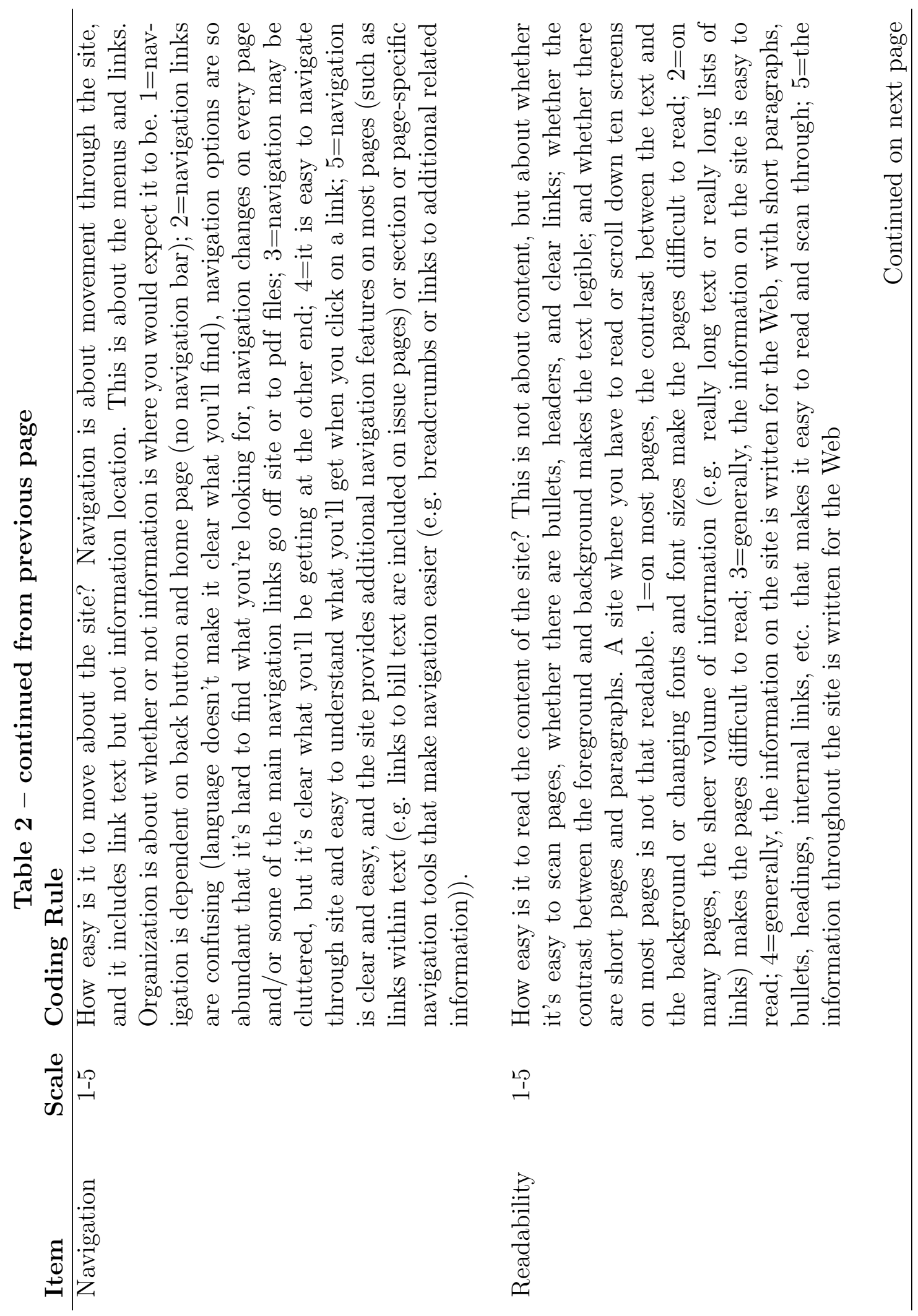




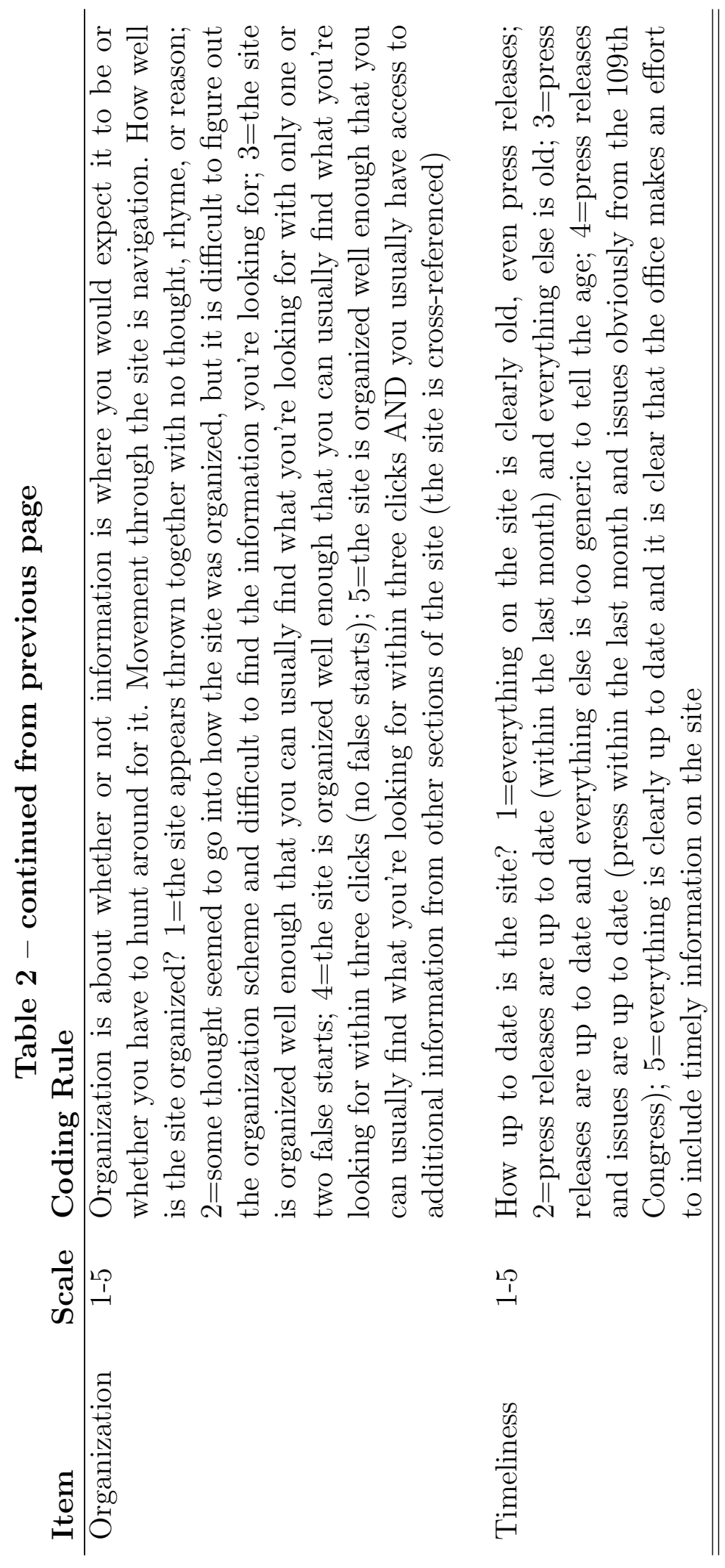


the website, its Navigability, its Readability, the website's Organization, and the Timeliness of the information content on the website. Finally, we use all 11 of these outcome variables to construct a single factor scale for the latent technological quality of the website using an ordered item response model. These items all load strongly on a single underlying factor (factor scores not reported).

\subsection{Network Adjacency Data}

We expect that the diffusion of the quality of members' websites will depend to some extent on informal social communication within the Congress. Following the discussion above, in this paper we measure informal networks by memberships in state delegations. To construct this network variable, we simply constructed a matrix with rows representing members, columns with labels that are identical to the rows, cells $[i, j]$ equal to one if members in row $i$ and column $j$ are in the same state, and cells equal to zero if members $\mathrm{i}$ and $\mathrm{j}$ are in different states ${ }^{6}$ Our quasi-experimental design also requires a matrix of district adjacencies. This matrix is similar to the state delegation matrix, with the exception that the cells are equal to one if two members' districts are adjacent, and zero otherwise..$^{7}$

For the spatial statistical models we report below, it is possible for the precision of estimated correlation parameters to be a function of the average density of the adjacency matrix, where the average density is the total number of ones divided by the number of matrix cells. The average density of the state delegation adjacency matrix is 0.042 , while the average density of the district adjacency matrix is 0.023 . To test the robustness of our results below to variation in network density, we constructed a supplemented district adjacency matrix that equals one if two districts are either adjacent to each other or are within one district

\footnotetext{
${ }^{6}$ Note on how we handle zero rows.

${ }^{7}$ Generating the matrix of district adjacencies takes some doing. We downloaded the GIS shapefile of congressional districts for the $109^{t h}$ Congress from the USGS National Atlas website. Unfortunately, this shape file does not represent districts, but instead represents smaller polygons that, when aggregated, reconstruct a congressional district, and obviously adjacencies among these polygons are not of any use for this analysis. Aggregating the data up to the district level turned out to be a very complex task, requiring over a hundred lines of $\mathrm{R}$ code. The $\mathrm{R}$ script to do this is available from the authors on request.
} 
of each other (i.e., on a two step path). The average density of this supplemented district adjacency matrix is 0.064 . Thus the two district adjacency matrices create density bounds below and above the state delegation density. We find little difference in the estimates for district adjacency across these two distance measures, so below to simplify the discussion we only present the results on the former, single-step adjacency matrix.

It is worth noting that the USGS data from which the district adjacencies are constructed include non-voting delegates from D.C., Puerto Rico and the Virgin Islands, but for some reason not the ones from Guam and American Samoa. Thus, our effective sample is 438 (435 regular members plus three non-voting delegates).

\subsection{Control variables}

We hold constant two variables that in previous work (Esterling et al., 2005) we found to have an effect on the quality of legislative websites. In the model below we refer to these as the fixed effect variables. Members who have longer terms in office tend to make less effective use of website technology $\left.\right|^{8}$ To control for this, we include a measure the equals one if the member is a Freshmen and zero otherwise (mean 0.096, standard deviation 0.295). In addition, the institutional context within Congress also can create advantages and disadvantages for members to undertake new initiatives. We control for the member's political party by including a variable that equals one if the member is a Republican (the majority party in 2006) and zero otherwise (mean 0.533, standard deviation 0.499).

\footnotetext{
${ }^{8}$ Members gain greater electoral security with longer tenure in office due to the well-known incumbent advantages (Jacobson, 1987, 26). Members with longer tenures in office have fewer incentives to seek out innovative ways to interact with constituents through their websites than those with shorter tenures. Members with longer tenures also are more likely to have well-established ways of communicating with constituents (Arnold, 2004) and thus are unlikely to place much effort in this new form of legislative communication.
} 


\section{Estimation}

We hypothesize that a member's effective use of website communication technologies depends on the propensity of other members in her state delegation to use these technologies, and these other members themselves are in the same estimation sample. Because of this stochastic dependence among members' websites, using ordinary probit to examine the relationship between a member's adoption practices and the average of the outcomes of the individuals that person interacts with would result in an estimate of social influence that would be biased upwards. The statistical literature on geographically connected processes has devised techniques to study spatial inter-dependencies in a way that appropriately accounts for these reciprocal effects Anselin, 1988, Cliff and Ord, 1981; Doreian, 1980). For this paper we estimate network dependence with a conditionally autoregressive (CAR) model (Congdon, 2003, chapter 7) using Bayesian MCMC sampling to simulate a posterior distribution of all model parameters. The basic model is:

$$
\left.\begin{array}{rl}
O_{i} & \sim \text { Categorical }\left(p_{i, 1 \ldots 5}\right) \\
p_{i, 1} & =1-q_{i, 1} \\
p_{i, 2} & =q_{i, 1}-q_{i, 2} \\
p_{i, 3} & =q_{i, 2}-q_{i, 3} \\
p_{i, 4} & =q_{i, 3}-q_{i, 4} \\
p_{i, 5} & =q_{i, 4} \\
\operatorname{logit}\left(q_{i, 1}\right) & =b_{1} \cdot x_{1, i}+b_{2} \cdot x_{2, i}+a_{i}+s_{i}-k_{1} \\
\operatorname{logit}\left(q_{i, 2}\right) & =b_{1} \cdot x_{1, i}+b_{2} \cdot x_{2, i}+a_{i}+s_{i}-k_{2} \\
\operatorname{logit}\left(q_{i, 3}\right) & =b_{1} \cdot x_{1, i}+b_{2} \cdot x_{2, i}+a_{i}+s_{i}-k_{3} \\
\operatorname{logit}\left(q_{i, 4}\right) & =b_{1} \cdot x_{1, i}+b_{2} \cdot x_{2, i}+a_{i}+s_{i}-k_{4} \\
a_{i} & \sim \phi\left(\bar{a}_{i}, 1\right) \\
\bar{a}_{i} & =\rho_{a} \cdot \sum_{k=1}^{N_{a i}}\left(\mathrm{Wa}_{i k}\right) /\left(N_{a i}\right) \\
\mathrm{Wa}_{i k} & \in\left\{a_{j}: \mathrm{j} \text { is adjacent to i }\right\} \\
N_{a i} & =\#\left\{a_{j}: \mathrm{j} \text { has an adjacent district to i }\right\} \\
s_{i} & \sim \phi\left(\bar{s}_{i}, 1\right) \\
\bar{s}_{i} & =\rho_{s} \cdot \sum_{k=1}^{N_{s} i}\left(\mathrm{Ws}_{i k}\right) /\left(N_{s i}\right) \\
\mathrm{Ws}_{i k} & \in\left\{s_{j}: \mathrm{j} \text { is in the same state delegation as i }\right\} \\
N_{s i} & =\#\left\{s_{j}: \mathrm{j} \text { is in the same state delegation as i }\right\}
\end{array}\right\} 1 \leq N
$$




$$
\begin{aligned}
\rho_{a} & \sim \operatorname{Uniform}(0,0.99) \\
\rho_{s} & \sim \operatorname{Uniform}(0,0.99) \\
b_{1} & \sim \phi(0.0,1.0 \mathrm{E}-5) \\
b_{2} & \sim \phi(0.0,1.0 \mathrm{E}-5) \\
k_{1} & \sim \phi(-1,0.1) C\left(-5, k_{2}\right) \\
k_{2} & \sim \phi(-0.5,0.1) C\left(k_{1}, k_{3}\right) \\
k_{3} & \sim \phi(0.5,0.1) C\left(k_{2}, k_{4}\right) \\
k_{4} & \sim \phi(1,0.1) C\left(k_{3}, 5\right)
\end{aligned}
$$

The set of equations contained within the outermost bracket give the model likelihood. We estimate the model separately for each ordered indicator, $O_{i}$, measuring the presence of each website quality or feature listed in table 1; each is modeled with an ordered logit function. Note the dichotomous outcome variables are also ordered so we use the same equation but estimate only one threshold. The conditional probability of each outcome is taken to be a function of the two fixed effect control variables, $\mathbf{x}$, their estimated coefficients, b, a category-specific threshold $k_{j}$, and the two random intercepts, $a_{i}$ and $s_{i}$. Here, $a_{i}$ is a random effect that captures local-level heterogeneity, and $s_{i}$ is a random effect that captures dependence among members of a state delegation.

To see that $a_{i}$ and $s_{i}$ are random intercepts capturing local- and state-level dependence, respectively, note that these two variables are themselves a function of other members' random intercepts. For each member, define the district-level adjacency set of member $i$ as the set of members $j$ with a one in the $i^{\text {th }}$ row of the district adjacency matrix. Define the state delegation of member $i$ as the set of members $j$ with a one in the $i^{\text {th }}$ row of the state adjacency matrix. The random intercept $a_{i}$ is assumed to have a normally distributed prior, with mean a function of the random intercepts of the member's district adjacency set (this is known as a CAR prior). The random intercept $s_{i}$ is assumed to have a normally distributed prior, with mean a function of the random intercepts of the member's state delegation. Inference for the social network effects are based on $\rho_{a}$ and $\rho_{s}$, both scalars. $\rho_{a}$ is the effect of a change in the probability a member's website will have one of the features or characteristics in table 1 is associated with the propensity of the websites of those that are in the member's district adjacency set to also have the feature or characteristic. 
This propensity is based on a weighted average with weight equal to $N_{i}$, or the number of elements in the member's district adjacency neighborhood set. Likewise, $\rho_{s}$ is the effect of a change in the propensity of a member's website to have a feature or characteristic associated with the propensity of the websites of those that are in the member's state delegation to have the feature or characteristic. Each $\rho$ is a spatial correlation parameter that captures the degree of spatial dependence at each geographic level (district and state). Because we control for district level heterogeneity via $a_{i}, \rho_{s}$ captures the causal dependence among the websites of members within a state delegation 9

To round out the analyzes, below we extend this model in two ways. First, we create an overall summary measure of the quality of the communication technology on each member's website using an ordered item response model, and embed this model into the main model to construct a full structural equation model (SEM). This SEM allows us to test for the dependence of the aggregate or latent quality of website technologies using all of the indicators simultaneously. Second, we create an interaction between the member's political party and the network dependence random effect to test whether diffusion is more prevalent within either of the political parties. This requires breaking the conditional mean of the state diffusion random intercept distribution into two terms: $\rho_{R_{s}} \cdot \operatorname{Republican}_{i} \cdot s_{i}$ and $\rho_{D_{s}} \cdot\left(1-\right.$ Republican $\left._{i}\right) \cdot s_{i}$.

For estimation, we use the MCMC Gibbs sampler in WinBUGS (Spiegelhalter, Thomas, Best, and Gilks, 1996). We assume diffuse priors for $\mathbf{b}$ to minimize the influence of the prior parameter distributions on the posteriors. We sample three chains and initialize each chain with overdispersed starting values. We discarded the first 5,000 iterations to allow burn-in, and then sampled an additional 5001 draws for each chain, keeping one in every ten draws, for a total sample of 1503 across the three chains. The chains show extremely good mixing using the Brooks-Gelman-Rubin diagnostic (Gelman and Rubin, 1992). Below we present

\footnotetext{
${ }^{9}$ The correlation parameters in principal can take values in the range $[-1,1]$. In the model, we constrain each $\rho$ to be positive, since a priori it is not plausible under either the diffusion or the heterogeneity hypothesis that members would systematically be dissimilar with their neighbors.
} 
the marginal posterior distributions of the model parameters.

\section{$6 \quad$ Findings}

One advantage of Bayesian estimation is that the results are reported in full marginal distributions, rather than as summaries of distributions in the form of point estimates and standard errors. Thus, one can evaluate the significance of parameter estimates by comparing their posterior distributions without relying on strict (frequentist) hypothesis tests. In this paper, we present these posterior distributions graphically as empirical cumulative densities and compare these densities to the priors as well as across parameters.

The results of the basic model for the 11 outcomes and the overall latent variable are shown in figure 2. The results are shown as comparisons of empirical cumulative density functions for the two spatial dependence parameters, $\rho_{a}$ and $\rho_{s}$. See the appendix for specific guidance on interpreting comparisons between cumulative density functions. In each figure, we graph the posterior distribution for the heterogeneity dependence parameter for the district adjacency matrix, $\mathrm{F}\left(\rho_{a}\right)$ in blue, and the cumulative density for the parameter capturing diffusion within state delegations, $\mathrm{F}\left(\rho_{s}\right)$ in maroon. The cumulative distribution for the uniform prior on $[0,0.9]$ for each of these parameters is shown as a dashed grey line. In this application, a rho with a cumulative density that is to the right of the dashed line indicates that there is a positive dependence at that geographic level, and a one with a cumulative density to the left of the dashed line indicates no dependence or a very low level of dependence. We test for the difference between distributions using the Kolmogorov-Smirnov (KS) test.

First, each of the posterior distributions is statistically different from the priors (the probability level for each KS test is less than 0.001). Note, however, that all of the cumulative densities for $\rho_{a}$ lie to the left of the prior, indicating that there is little to no dependence at the district level. This means that there are few geographically distributed variables that 

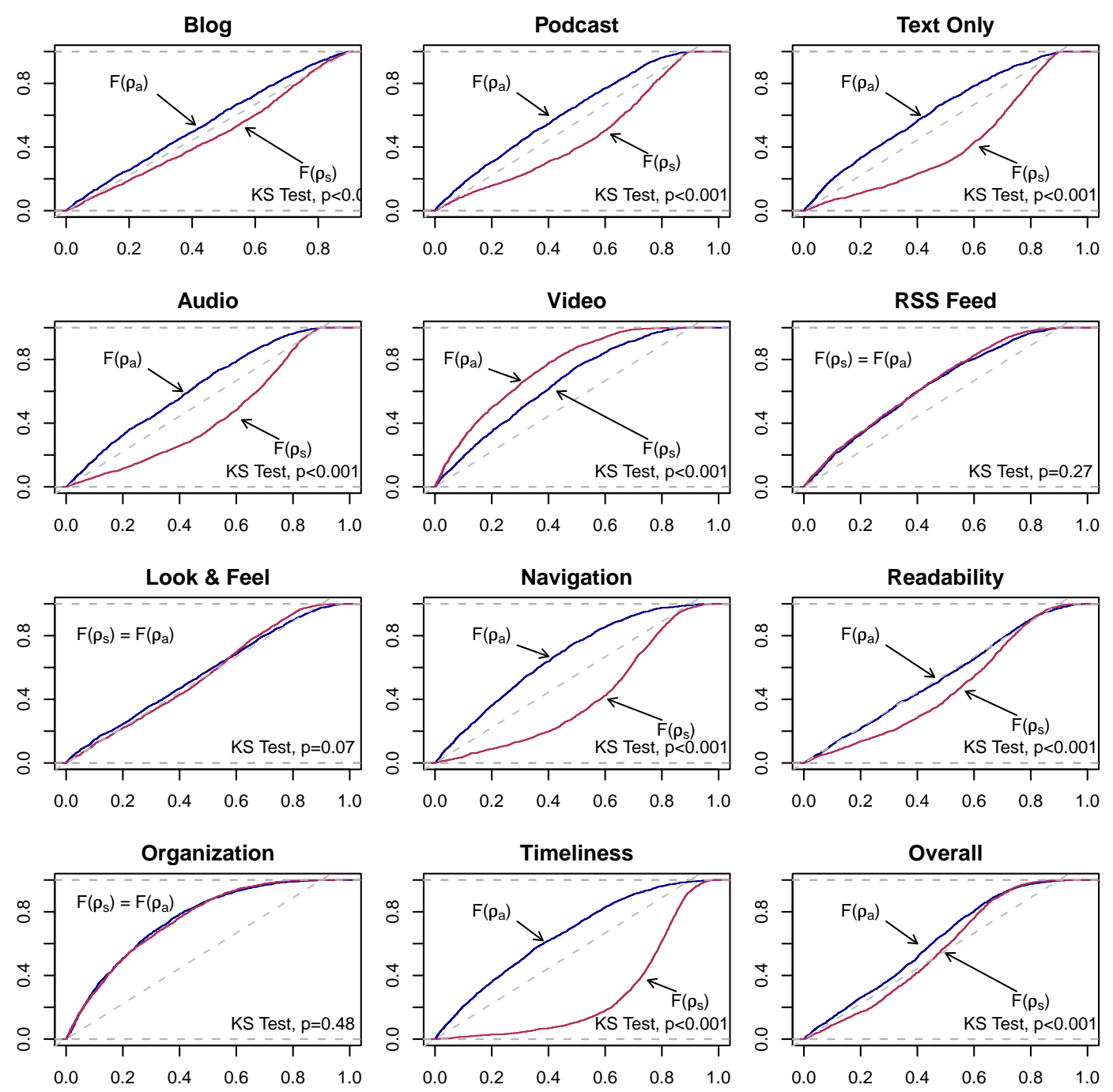

Figure 2: The Basic Results

This figure compares the posterior distributions for the estimated effects of state delegation $\left(\rho_{s}\right)$ and district adjacency $\left(\rho_{a}\right)$. F (.) indicates the cumulative posterior distribution for each $\rho$ parameter. A cumulative distribution to the right indicates a higher mode for the parameter. The dashed grey line is the cumulative prior distribution for each parameter. The KS test in each frame is the test for the difference between the two posteriors. 
are correlated with the adoption of new website technologies.

In contrast, many of the cumulative densities for $\rho_{s}$ are significantly to the right of both the prior as well as to the posteriors for $\rho_{a}$. This indicates that for these items, there exists dependence within state delegations. In particular, we observe dependence within state delegations for podcast, text only, audio, navigation, readability, and timeliness. Notably, we do not see a dependence for overall score, which suggests that the dependence is at the feature level rather than at a deeper, latent quality level. That is, the fact other members in a state have high quality (feature rich) sites does not drive a member of the state delegation to have a feature rich site - rather, the presence of a particular feature would drive you to have that specific feature (for the subset of features where we find dependence).

To test whether diffusion occurs differently within the political parties, we re-ran the same model including interactions to allow each rho parameter to differ for each party. We report the results for this model in figure 3. There is very little that is different between the two political parties with the exception for a few items where there appears to be slightly more dependence for Democrats than for Republicans. These items are audio, look and feel, organization, and the overall summary measure. Finally, consider the effect estimates for the fixed effect regression parameters, reported in table 3. The freshmen (elected in 2004) tend to score higher on the general technical measures of look and feel, navigation, readability, organization and timeliness.

More importantly, the fixed effect results for party suggest that, while there are different diffusion patterns within the parties, the two parties overall have similar average amounts of communication technology on their websites, with Republicans having a slightly higher propensity for a few items (text only, audio, a high look and feel rating, and a timeliness rating). This implies that while there exists more dependence among Democratic members within state delegations, this dependence does not necessarily improve the quality of websites. Indeed, the correlation implies that, especially among Democrats, a member with a low quality website will drive down the quality of the websites of others in the delegation. 

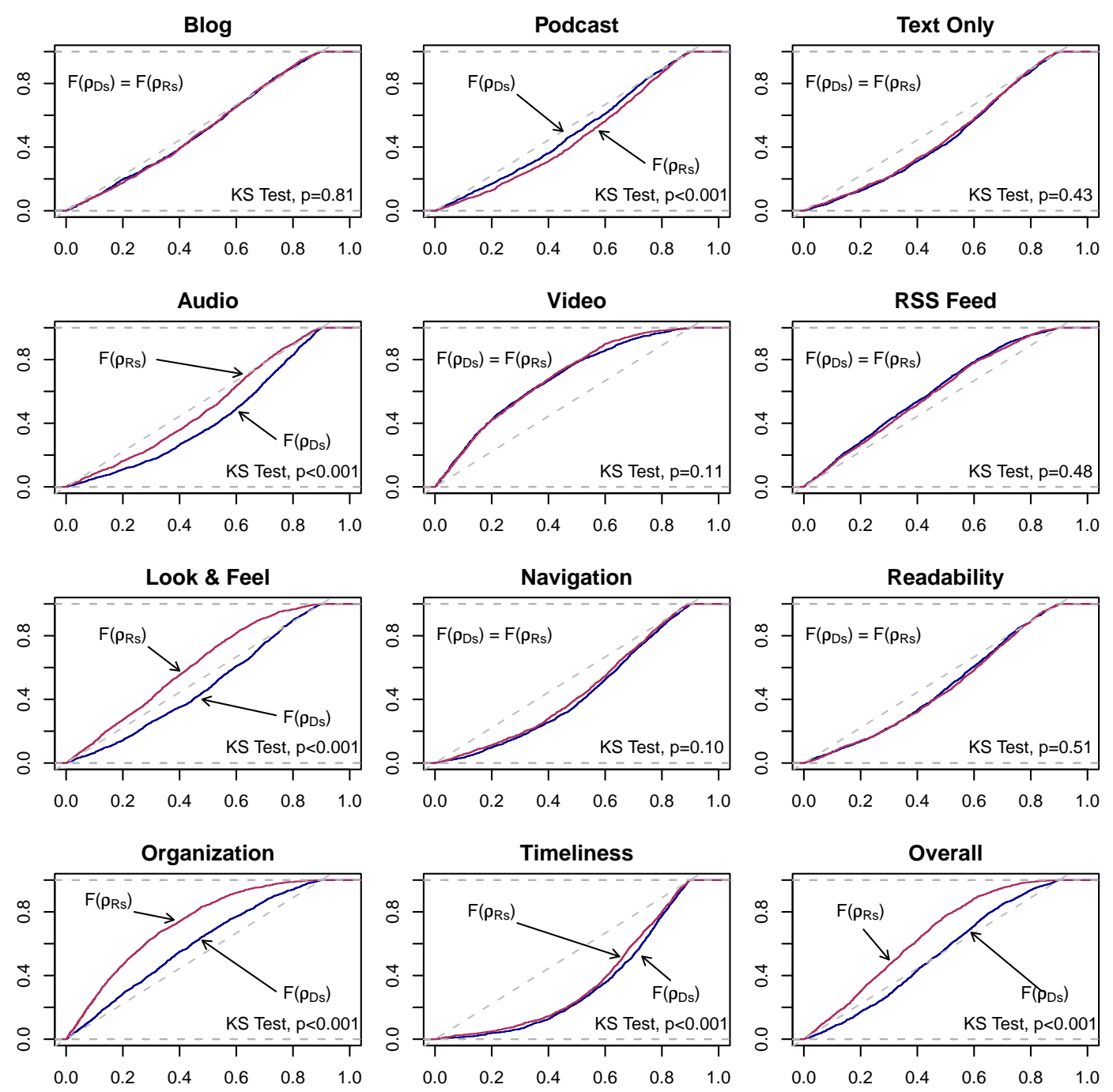

Figure 3: The Results Estimated Separately for Each Party

This figure compares the degree of diffusion within state delegations separately for each political party. $\rho_{D_{s}}$ is the posterior distribution for the state delegation diffusion parameter for Democrats, and $\rho_{R_{s}}$ is the same for Republicans. A cumulative distribution to the right indicates a higher mode for that party. KS tests compare the two posteriors in each graph. 
Table 3: Model Fixed Effects Results

\begin{tabular}{lcrrr} 
& \multicolumn{2}{c}{ Freshman } & \multicolumn{2}{c}{ Party $(\mathrm{R}=1)$} \\
\cline { 2 - 5 } & $\beta$ & $S E(\beta)$ & \multicolumn{1}{c}{$\beta$} & $S E(\beta)$ \\
\hline Blog & 0.22 & $(0.57)$ & 0.44 & $(0.37)$ \\
Podcast & 0.49 & $(0.57)$ & -0.58 & $(0.39)$ \\
Text Only & $-1.3^{*}$ & $(0.34)$ & $1.0^{*}$ & $(0.37)$ \\
Audio & -0.21 & $(0.45)$ & $0.74^{*}$ & $(0.28)$ \\
Video & 0.38 & $(0.36)$ & -0.09 & $(0.22)$ \\
RSS Feed & -0.01 & $(0.51)$ & -0.32 & $(0.24)$ \\
Look \& Feel & $0.99^{*}$ & $(0.40)$ & $0.48^{*}$ & $(0.24)$ \\
Navigation & $0.88^{*}$ & $(0.40)$ & 0.18 & $(0.24)$ \\
Readability & $1.0^{*}$ & $(0.41)$ & 0.21 & $(0.23)$ \\
Organization & $0.86^{*}$ & $(0.42)$ & 0.29 & $(0.24)$ \\
Timeliness & $1.2^{*}$ & $(0.41)$ & $0.46^{*}$ & $(0.23)$ \\
\hline
\end{tabular}

$N=438,{ }^{*} p<.05$

\section{Triangulating the Results using Survey Data and In- terviews}

We triangulate the findings of the spatial diffusion models using the results of a winter, 2007, survey of the Congressional staff in charge of the members' official websites. Out of 440 offices surveyed, we received 100 responses (23 percent). We asked respondents, “Among other Members of Congress' websites, are there ones that stand out to you as especially good? If yes, which do you think are particularly good?" Only 52 offices were named (some offices were mentioned multiple times. Of those 52, 86 percent were within the same party, and (when combined with 11 responses indicating the state delegation), 60 percent were within the same state delegation 10 We treated these as egocentric data, assuming independence across respondents.11 We label the nominating office the "ego" and the potentially nominated website the "target." In this model, each ego could possibly name

\footnotetext{
${ }^{10}$ We also asked about who the Member was friends with, with similar results: of 90 "friends" named, 87 percent were same party, and 44 percent were same state.

${ }^{11}$ Standard methods to analyze whole network data, such as MRQAP and $\mathrm{p}^{*}$, are not appropriate because of the low response rate. However, the independence assumption is still problematic-e.g., if A names B, this may mean $\mathrm{C}$ is more likely to name $\mathrm{B}$ as well. We will address this estimation issue in future editions of this paper.
} 
Table 4: Logistic (rare event) results for naming other offices

\begin{tabular}{lcc} 
Variable & Coef. & Std. Err. \\
\hline Same Party & $1.57^{*}$ & .54 \\
Same State & $1.52^{*}$ & .41 \\
Adjacent Districts & .33 & .66 \\
Target is a Leader & $1.04^{*}$ & .34 \\
The Term for Target & -.02 & .04 \\
Target is a Democrat & -.61 & .56 \\
Ego is a Democrat & .77 & .55 \\
Constant & $-8.50^{*}$ & .63 \\
\hline
\end{tabular}

$N=52767 ;^{*} p<0.05$.

Note: The model also controls for the CMF ratings of the quality of both ego's website and the potential target's website (results not reported).

any of the potential targets, and given the sparseness of the data, we specified a rare events logit model (King and Zeng, 2001). For covariates, we use Same party indicating both ego and potential target are in the same party; Same state indicating both are in the same state delegation; Adjacent district indicating the districts are geographically adjacent; whether the potential target is a Party leader; the potential target's Term or length of service; whether the potential Target is a Democrat; and whether the Ego is a Democrat ${ }^{12}$

The logistic regression confirms that state delegation was a powerful predictor that one office would name another $(p<.001)$, while district adjacency (when controlling for same state delegation) was not significant. Also important were whether both offices were from the same party, whether the named offices was from party leadership leadership.

\subsection{Interview Qualitative Data}

We also conducted structured interviews on information sharing processes among offices in the summer of 2006 involving 99 offices. These interviews were transcribed and coded in

\footnotetext{
${ }^{12} \mathrm{We}$ also include a battery of controls for the quality rating of each website (for both ego and target) along a variety of dimensions, such as the quality of the issue content, constituency service, technology, etc. (results not reported).
} 
NVivo. The interview data also support the proposition that there was a powerful emulation process within state delegations. As one staff person stated, "I was not in the business of trying to reinvent the wheel." There are two pathways by which offices may affect each other: interpersonal communication and passive mimicry. That is, some staff merely look at other websites, while others talk to each other about the features of the websites. The following interviewee illustrates diffusion both through mimicry and interpersonal communication:

We looked at every single website .... We probably had [a list of] the top 30 sites. I individually contacted every single one of those offices, and found out, who do you use for your website, who does the upkeep of it, who designed it, got all of the specifics of it ...

While the interview data make clear that both processes of diffusion existed, it is clear that mimicry dominated interpersonal communication, where the following statement is representative:

I didn't talk to other staff members. I definitely looked at other Members' sites very carefully and tried to see what, what they were doing that might work for us.

Strikingly, only one office out of ninety nine reported talking extensively to other offices about internal processes (e.g., website design; how to get content on the website, etc.). Interpersonal communication was generally limited to identifying vendors, where the following two responses are typical:

We've looked at basically every other member site there is ... [W]e picked out the ones we liked the best, and I contacted their staff, and we found out who their ... vendor was.

I mean, I just talked to a bunch of my friends that are press secretaries basically. I just called them and said hey, who do you guys use, or, you know, is there anything you'd recommend? I really like your site, who did you use? Yeah, you know, basically word of mouth. [Name] did the same, our chief of staff. And he talked to some other chiefs of staff, in terms of cost and benefits, and customer service.

These last two quotes illustrate two different strategies for identifying who to talk to. The first relied on an extensive search of what was observable to guide personal contact. The 


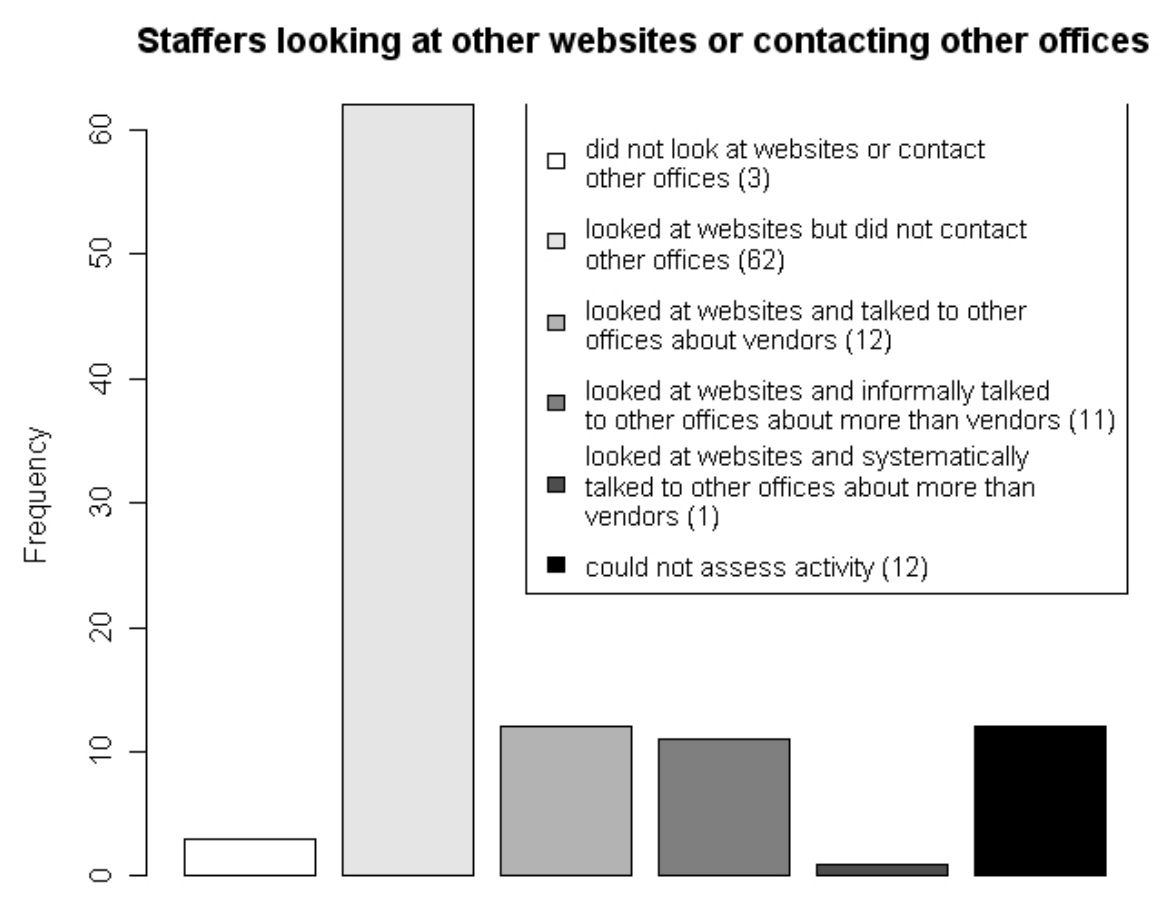

Figure 4: Emulation Process in Congress

second indicates a reliance on friends, that is, a particular type of interpersonal network, friendship, guided interpersonal information seeking. Our interview data suggests that interpersonal information seeking was significant (23 percent indicated talking to other offices), but the dominant mode of learning from what other offices were doing was mimicry - just looking at other websites. Figure 4 summarizes the distribution of social learning strategies we observed among the people we interviewed (based on a coding of their responses to our structured interviews).

\section{Discussion and Conclusion}

The above analyses provide insight into the pathways of innovation within Congress, where the different data sources provide a degree of triangulation as to what the underlying processes are. We find a significant possibility of diffusion within state delegations. The results of the analysis of the spatial dependence are highly suggestive, but we admit the possibility 
of confounding variables that are conditioned on state boundaries. However, the two other data sources further bolster the relative plausibility that diffusion is driving this dependence. Specifically, we conducted a social network survey of the staff in charge of their Member's website, and we found that being in the same state delegation was a powerful predictor of a tie between two offices, while adjacency was not. The interview data further confirms the interdependence of website features, highlighting a primary role for mimicry (looking at and copying what other offices have done), and a secondary role for interpersonal communication. The pattern of spatial dependence also reinforces this conclusion, where the feature of a website that is most quickly evaluated by a harried communication director-its timeliness-is also the feature that shows the strongest sign of diffusion.

This is our first cut at these data. There are several obvious lines we intend to pursue. First, we wish to model diffusion across different possible informal communication networks, including cosponsorship networks (Fowler, 2006), committee overlap networks (Baughman, 2006), and hallway proximity networks, which would measure the physical distance between members' offices. The latter has the interesting feature that the selection of members to offices is likely exogenous to other informal networks, ruling out the inferential problems stemming from homophily, or the problem that members connected in informal networks also share attributes (or the non-geographic version of spatial heterogeneity that we discuss above). Second, the CMF dataset has a very rich set of indicators of a variety of attributes of members websites, which allows test across substantive categories of variables, as well as tests of the diffusion of latent properties of websites that could be captured in spatial latent variable autoregressive models.

Third, we are refining the alignment between the survey and the analysis of spatial dependence-for example, the survey suggests that there should be greater dependence among individuals from the same party member, which we should be able to test directly. Finally, there are a variety of priors in addition to CAR one can assume to model the diffusion process, and we hope to test the robustness of our results across these different priors. 


\section{A Appendix: Interpreting Comparisons between Em- pirical Cumulative Density Functions}

Figures 2 and 3 report the results of the statistical models in terms of comparisons of the posterior distributions of the spatial dependence parameters. Here we walk the reader though how to read such a graph, using the results for Podcast as the example. Figure 5 shows the Podcast figure enlarged, and with some more detail given. In this figure, each curve shows the empirical cumulative posterior (or estimated) density for a model parameter. The top (blue) line shows the cumulative density for $\rho_{a}$, which is the estimated degree of spatial dependence among adjacent congressional districts. The bottom (maroon) line is the cumulative density for $\rho_{s}$, which is the estimated degree of diffusion of website practices within state delegations (holding constant district level heterogeneity). The dashed grey line indicates the cumulative prior distribution for each of these parameters. The figure shows both how each posterior differs from the prior, as well as how much the distribution for each parameter differs from each other.

To understand differences between cumulative distributions, it is sometimes easier to first consider how the densities differ, and then consider how changes in densities changes the shape of the cumulative distribution function. Figure 6 shows the smoothed posterior densities for each of the two $\rho$ parameters, along with the uniform prior density for each. First consider the prior Uniform [0,1] density, drawn in grey, where the density accumulates from zero to one in a linear manner. For this density, the cumulative distribution function is a straight line connecting the origin to the point $(1,1)$, and is indicated with a dashed grey line in figure 5 .

Next consider the posterior density for $\rho_{a}$. This density has a mode close to zero and is skewed to the right. This posterior distribution indicates that there is little if any dependence in this process that result from district adjacency; the spatial correlation at the district level is approximately zero. In this case, moving from left to right in figure 5 , the density accumulates quickly at first, and then tapers off, resulting in a cumulative distribution function that has 


\section{Example Graph for Cumulative Posterior Densities}

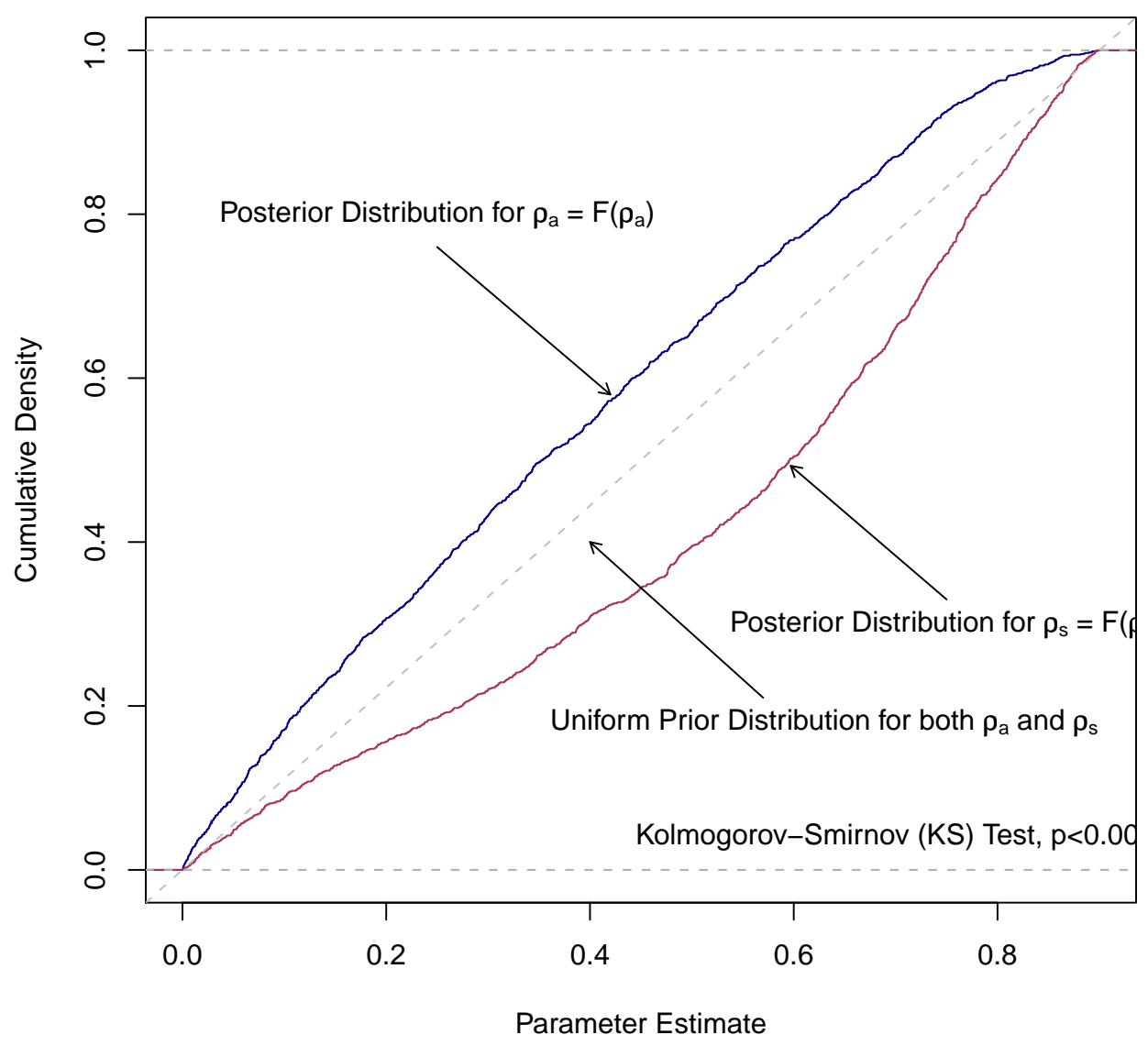

Figure 5: How to interpret the results in figures 2 and 3

a steep slope close to zero and a relatively flat slope above about 0.6 . Finally consider the posterior density for $\rho_{s}$, which has a mode at about 0.8 . This indicates that there is stronger evidence that dependence exists within a state delegation; the probability that the spatial correlation is above 0.5 is quite high. In this case, moving from left to right in figure 5 , the cumulative distribution function is relatively flat at low values for the parameter estimate, and then is steep starting around 0.5.

In general, a cumulative distribution function that is to the lower-right indicates a high correlation estimate, that is, a density that is concentrated at the high range of possible parameter values. A cumulative distribution function that is to the upper-left indicates 


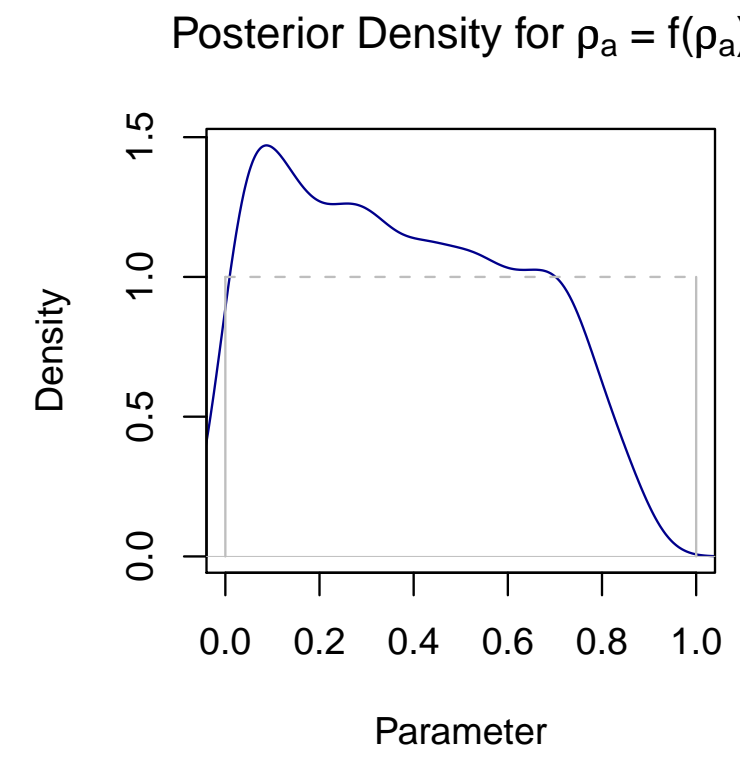

Posterior Density for $\rho_{s}=f\left(\rho_{s}\right)$

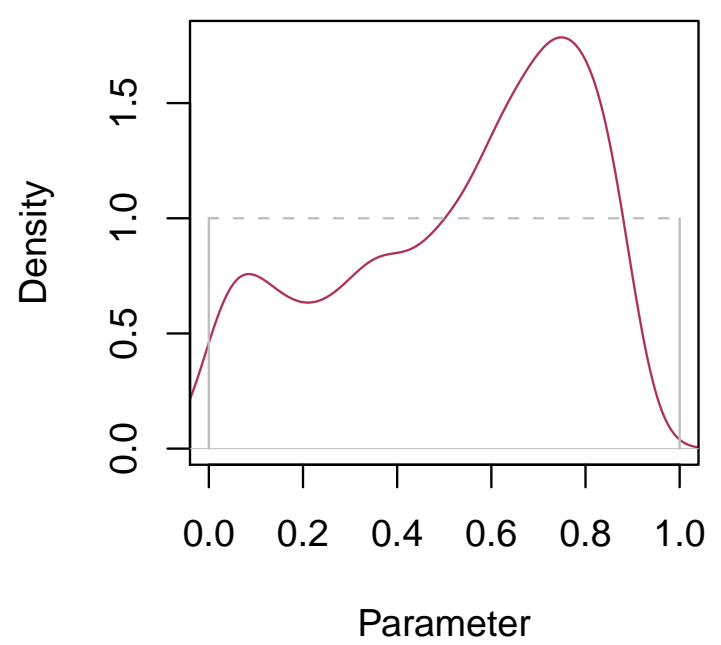

Figure 6: Prior and posterior densities for $\rho_{a}$ and $\rho_{s}$

a low correlation estimates, or a density that is concentrated at a low range of possible parameter values. Finally, the farther a cumulative distribution is from the grey dashed line, the more that has been gleaned about the process from the data; cumulative distributions that are close to the grey line indicate we have learned nothing beyond the prior beliefs used to define the model.

Finally, the cumulative distribution graphs also report the p-value for a KolmogorovSmirnov test for the equality of the posterior distributions for $\rho_{a}$ and $\rho_{a}$. A low p-value indicates that the two distributions are different.

\section{References}

Allen, T. J. (1978). Managing the Flow of Technology: Technology Transfer and the Dissemination of Technological Information within the RED Organization. Cambridge, Mass.: MIT Press.

Anselin, L. (1988). Spatial Econometrics: Methods and Models. Boston, Mass.: Kluwer Academic. 
Arnold, L. W., R. Dean, and E. Al (2000). Friendship and votes: The impact of interpersonal ties on legislative decision making. State and Local Government Review 32, 142-147.

Arnold, R. D. (2004). Congress, the Press, and Political Accountability. Princeton, N.J.: Princeton University Press.

Baughman, J. (2006). Common Ground: Committee Politics in the U.S. House of Representatives. Palo Alto, Calif.: Stanford University Press.

Caldeira, G. A. and S. C. Patterson (1987). Political friendships in the legislature. Journal of Politics 49, 953-975.

Carpenter, D. P., K. M. Esterling, and D. M. Lazer (1998). The strength of weak ties in lobbying networks: Evidence from health care politics in the united state. Journal of Theoretical Politics 10(Oct.), 417-444.

Carpenter, D. P., K. M. Esterling, and D. M. Lazer (2003). Information and contact making in policy networks: A model with evidence from the u.s. health policy domain. Rationality and Society 15 (Nov.), 411-440.

Carpenter, D. P., K. M. Esterling, and D. M. Lazer (2004). Friends, brokers, and transitivity: Who informs whom in washington politics? Journal of Politics 66(Feb.), 224-246.

Cliff, A. and J. Ord (1981). Spatial Processes: Models and Applications. London: Pion.

Coleman, J. S., E. Katz, and et al (1957). The diffusion of an innovation among physicians. Sociometry 20(4), 253-270.

Congdon, P. (2003). Applied Bayesian Modelling. Hoboken, N.J.: John Wiley \& Sons, Ltd.

den Bulte, C. V. and R. Moenaert (1998). The effects of r\&d team co-location on communication patterns among r\&d, marketing, and manufacturing. Management Science 44(11), S1-S18.

DiMaggio, P. J. and W. W. Powell (1983). The iron cage revisited - institutional isomorphism and collective rationality in organizational fields. American Sociological Review 48(2), $147-160$.

Doreian, P. (1980). Linear models with spatially distributed data: Spatial disturbances or spatial effects? Sociological Methods and Research 9, 29-60.

Druckman, J. N., C. L. Hennessy, M. J. Kifer, and M. Parkin (2009). Issue engagement on congressional web sites, 2002-2006. Social Science Computer Review 27(June), 1-21.

Druckman, J. N., M. K. Kifer, and M. Parkin (2007). The technological development of congressional candidate websites: How and why candidates use web innovations. Social Science Computer Review 25, 425-442. 
Esterling, K. M., D. M. Lazer, and M. A. Neblo (2005). Home (page) style: Determinants of the quality of house members' websites. International Journal of Electronic Government Reserach 1(2), 50-63.

Fenno, R. F. (1978). Homestyle: House Members in Their Districts. Boston, Mass.: Little, Brown and Co.

Festinger, L. (1950). Informal social communication. Psychological Review 57(5), 271-282.

Fowler, J. H. (2006). Legislative cosponsorship networks in the u.s. house and senate. Social Networks 28(Oct.), 454-465.

Galaskiewicz, J. and R. S. Burt (1991). Interorganizational contagion in corporate philanthropy. Administrative Science Quarterly 36(1), 88-105.

Gelman, A. and D. B. Rubin (1992). Inference from iterative simulation using multiple sequences. Statistical Science 7(Nov.), 434-455.

Hagerstrand, T. (1967). Innovation Diffusion as a Spatial Process. Chicago, Ill.: University of Chicago Press.

Hansen, B. B. and J. Bowers (2008). Covariate balance in simple, stratified and clustered comparative studies. Statistical Science 23(2), 219-236.

Hansen, M. T. (1999). The search-transfer problem: The role of weak ties in sharing knowledge across organizational units. Administrative Science Quarterly 44(1), 82-111.

Haunschild, P. and A. Milner (1997). Modes of interorganizational imitation: The effects of outcome salience and uncertainty. Administrative Science Quarterly 42(3), 472-500.

Hedlund, R. D. (1984). Organizational attributes of legislatures: Structure, rules, norms, resources. Legislative Studies Quarterly IX(Feb.), 51-121.

Heinz, J. P., E. O. Laumann, R. L. Nelson, and R. H. Salisbury (1993). The Hollow Core: Private Interests in National Policymaking. Cambridge, Mass.: Harvard University Press.

Jacobson, G. C. (1987). The Politics of Congressional Elections. Boston, Mass.: Little, Brown and Co.

King, G. and L. Zeng (2001). Logistic regression in rare events data. Political Analysis 9 (Spring), 137-163.

Kraut, R. E., C. Egido, and et al (1990). Intellectual Teamwork: Social and Technological Foundations of Cooperative Work (Jolene Galegher, Robert E. Kraut, Carmen Egido ed.)., Chapter Patterns of Contact and Communication in Scientific Research Collaboration. Lawrence Erlbaum.

Laumann, E. O. and D. Knoke (1984). The Organizational State: Social Choice in National Policy Domains. Madison, Wisc.: University of Wisconsin Press. 
Lazer, D. M. (2001). Coevolution of network and individual. Journal of Mathematical Sociology 25(Jan.), 69-108.

Mintrom, M. (1997). Policy entrepreneurs and the diffusion of innovation. American Journal of Political Science 41(3), 738-770.

Monge, P., L. Rothman, and et al (1985). The dynamics of organizational proximity. Management Science 31(9), 1129-1141.

Pitkin, H. F. (1967). The Concept of Representation. Berkeley, Calif.: University of California Press.

Rice, R. and C. Aydin (1991). Attitudes toward new organizational technology: Network proximity as a mechanism for social information processing. Administrative Science Quarterly 36(2), 219-244.

Rogers, E. M. (1976). New product adoption and diffusion. The Journal of Consumer Research 2(4), 290-301.

Ryan, B. and N. Gross (1943). The diffusion of hybrid seed corn in two iowa communities. Rural Sociology 8, 15-24.

Salisbury, R. H. and K. Shepsle (1981). U.s. congressman as enterprise. Legislative Studies Quarterly VI(Nov.), 559-576.

Spiegelhalter, D., A. Thomas, N. Best, and W. Gilks (1996). Bugs 0.5: Bayesian inference using gibbs sampling manual (version ii). Technical report, MRC Biostatistics Unit.

Truman, D. B. (1956). State delegations and the structure of party voting in the united state house of representatives. American Political Science Review 50(Dec.), 1023-1045.

Valente, T. W. (1995). Network Models of the Diffusion of Innovations. Cresskill, N.J.: Hampton Press.

Walker, J. L. (1969). The diffusion of innovations among the american states. American Political Science Review 63(Sept.), 880-899.

Zahn, G. (1991). Face-to-face communication in an office setting: The effects of position, proximity, and exposure. Communication Research 18, 737-754. 